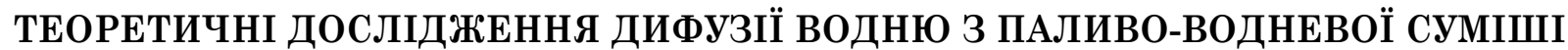

\begin{abstract}
Анотація. Використання паливо-водневих сумішей істотно знижуе кількість шкідливих викидів в відхідних газах ДВЗ. В роботі розглядаються особливості використання гомогенних паливо-водневих сумішей у двигунах внутрішнього згорання. Особливістю таких сумішей є рівномірне насичення воднем товщі рідкого палива за рахунок попереднього розчинення водню у паливі. Після подачі палива, насиченого воднем, у циліндр ДВЗ починається процес десорбції водню з краплі палива. На поверхні краплі палива виникає шар повітря з підвищеною концентрацією водню. Розроблена математична модель процесу десорбції водню з краплі паливо-водневої суміші. Біля краплі палива у пограничному шарі повітря виникає концентрація водню, яка перевищуе нижню межу концентрації самозаймання Н2. Це створюе умови проходження процесу горіння водню до початку займання палива, що інтенсифікуе процес нагріву краплі палива. Отримана регресійна залежність нагріву прикордонного шару повітря на поверхні краплі палива, в залежності від концентрації водню в паливі. При концентрації водню в паливі $1 \mathrm{~m}^{3} / \mathrm{M}^{3}$ перегрів прикордонного шару повітря біля краплі палива може досягати $150^{\circ} \mathrm{C}$, відносно середньої температури повітря у циліндрі ДВЗ за рахунок самозаймання водню. Оскільки основна маса водню залишається у паливі, то таку паливо-водневу суміш можна розглядати як більш легке паливо, ніж вихідне паливо.
\end{abstract}

Ключові слова: паливо, водень, гомогенна суміш, десорбція водню, дифузія водню.

Leybovych Lev, Yevstigneyev Yurii Admiral Makarov National University of Shipbuilding

\section{THEORETICAL STUDIES DESORPTION OF HYDROGEN FROM THE FUEL-HYDROGEN MIXTURE}

Summary. The use of fuel-hydrogen mixtures significantly reduces the amount of harmful emissions in the exhaust gases of the internal combustion engine. Namely, the content of soot by an average of 35\%, nitrogen oxides by $30 \ldots 40 \%$, carbon monoxide by $5 \%$, and diminished by $30 \%$. This indicates that the processes of combustion of diesel fuels are improved when hydrogen is added to them. Consider the use of homogeneous fuels-hydrogen mixtures in internal combustion engines. The peculiarity of homogeneous fuels-hydrogen mixtures is the uniform saturation of hydrogen with the thickness of liquid fuel due to the preliminary dissolution of hydrogen in the fuel. After the hydrogen saturated fuel is fed, the process of desorption of hydrogen from the fuel droplet begins in the ICE cylinder. A layer of air with high hydrogen concentration is created on the surface of the droplet of fuel. A mathematical model of the process of hydrogen desorption from a drop of fuel-hydrogen mixture is developed. The numerical solution of the differential equations of hydrogen diffusion for diesel fuel (hydrogen concentration in the pile of $0,4 \mathrm{~m}^{3} / \mathrm{m}^{3}$ ) and the average diameter of a droplet of $25 \mu \mathrm{m}$ gives a hydrogen diffusion zone at the fuel surface of about $1 \mu \mathrm{m}$ during the time from the moment of supply until the ignition of the fuel. The regression dependence of the depth of the hydrogen diffusion zone on the fuel droplet in the range of change of the diffusion coefficient value from $1 \cdot 10-9 . .10 \cdot 10-9 \mathrm{~m}^{2} / \mathrm{s}$ was obtained. Due to the process of desorption of hydrogen from the fuel in the boundary layer of air near the drop of fuel, a hydrogen concentration is created, which exceeds the lower limit of the concentration of self-ignition H2. And this creates the conditions for the process of combustion of hydrogen before the ignition of the fuel, which intensifies the process of heating the droplet. The regression dependence of the heating of the boundary layer of air at the surface of the droplet of fuel is obtained, depending on the concentration of hydrogen in the pile. For the concentration of hydrogen in a pile of $1 \mathrm{~m}^{3} / \mathrm{m}^{3}$, overheating of the boundary layer of air near a drop of fuel can reach $150^{\circ} \mathrm{C}$ relative to the average air temperature in the engine of the engine due to the spontaneous combustion of hydrogen. Since the bulk of hydrogen remains in the fuel, such a fuel - the hydrogen mixture can be considered as a lighter fuel than the original fuel.

Keywords: fuel, hydrogen, homogeneous mixture, hydrogen desorption, hydrogen diffusion.

$\Pi^{2}$ остановка проблеми. За типом паливоводневі суміші можуть бути гетерогенні та гомогенні. Найбільша кількість досліджень виконана по утворенню гетерогенних сумішей $[7 ; 8 ; 9 ; 13]$, автори яких додають водень безпосереднњо в циліндр двигуна або в паливну систему високого тиску.

Недоліки застосування гетерогенних сумішей $\epsilon$, ускладнення конструкції двигуна та організації робочого процесу. При такому сумішоутворенні можлива нестабільна робота ДВЗ, а саме: детонаційне займання, поверхневе запалювання, зворотні спалахи [10; 13].
Аналіз останніх досліджень i публікацій. На підставі результатів експериментальних досліджень виявлено, що при використанні водню товщина пристінного шару, в якому не відбувають-ся окислювальні процеси, зменшуеться приблизно в 5 разів. Внаслідок чого зростає повнота згоряння палива, і знижуеться емісія токсичних речовин [9; 13].

Дані наведені в $[2 ; 6]$, показують, що при використанні паливо-водневих сумішей істотно знижується кількість шкідливих викидів в відхідних газах ДВЗ. А саме, зміст сажі в середньому на $35 \%$, оксидів азоту на $30 . .40 \%$, окису вуглецю на $5 \%$. Це 
свідчить про поліпшення процесів горіння дизельних палив при додаванні в процес горіння водню.

Максимальна нормальна швидкість поширення полум'я повітряно-водневої суміші, при рівних умовах в 6,75 рази більше, ніж нормальна швидкість у сумішей дизельного палива чи бензину з повітрям, і складає 0,24...2,70 м/с [8].

Виділення невирішених раніше частин загальної проблеми. Процес інтенсивності утворення шару водню в повітрі біля поверхні краплі палива, залежить від умов десорбщії Н2 3 товщі краплі палива. Цей мало вивчений [3].

В роботі [3] зазначалося, що на поверхні краплі дизельного палива, насиченого воднем, виникають локальні осередки займання водню при температурі менше на $10 \ldots 12^{\circ} \mathrm{C}$ температури спалаху дизельного палива.

Можна припустити, що гомогенні суміші, які утворюються на етапі паливопідготовки зможуть усунути вище зазначені проблеми гетерогенних паливо-водневих сумішей. В гомогенних сумішах, десорбція водню з товщі палива відбувається безпосередньо в циліндрі двигуна. Це забезпечує максимальну концентрацію водню біля поверхні краплі палива і виключає критичні центри займання.

Прогнозування процесів самозаймання водню на поверхні краплі палива грунтуеться на вивченні процесів дифрузії Н2 в поверхневому шарі палива на кордоні контакту його 3 повітрям.

Формулювання цілей статті. Аналіз процесу десорбції водню з товщі краплі гомогенної паливо-водневої суміші в залежності від сорту палива та температури краплі.

Виклад основного матеріалу дослідження. Можливість прогнозувати процес дифозії при термічних і хімічних впливах, закладено в рішенні основного рівняння феноменологічної теорії дифузї - другому законі Фіка [5]. Було встановлено [4], що зона дифузії сірководню в краплині води при часі їі існування до 10 мс не перевищуе 2 мкм. Це дозволяе розглядати глибину зони дифрузії водню в паливо не більше 2 мкм при порівнянних значеннях коефріцієнтів дифрузії водню в воді.

Якщо розглядати процес дифрузії водню в елементарному об'ємі краплі палива (рис. 1 a), то в першому наближенні рівняння другого закону Фіка для одновимірного випадку можна записати у вигляді:

$$
\frac{d C}{d \tau}=D \frac{d^{2} C}{d x^{2}}
$$

де $C$ - концентрація речовини $\left[1 / \mathrm{M}^{3}\right] ; D-$ коефріціент дифрузії [м²/c]; $\tau$ - час [c]; $x$ - просторова координата [мкм].

Рівняння (1) є диференціальним рівнянням дифрузії (параболічного типу) в частинних похідних. Одним 3 найбільш універсальних для рішення таких диференціальних рівнянь у частинних похідних є метод кінцевих різниць.

Для рішення рівняння (1) методом кінцевих різниць визначимось 3 початковими та гранични- ми умовами. Для високої якості внутрішнього сумішоутворення, і рівномірного розподілу палива по всьому об'єму камери згоряння, середній діаметр крапель палива складає $d=20 . .25$ мкм [7-9]. Час існування краплі до моменту займання в малообертових ДВС становить 0,05...0,1 с, а високообертових ДВС 0,001...0,01 с [7]. Коефіціент дифузї̈ для водню можна прийняти $D=1 \cdot 10^{-9} . .10 \cdot 10^{-9} \mathrm{M}^{2} / \mathrm{c}[1]$.

Регресійну залежність коефіщіента дифузії для водню від температури, можна отримати на підставі даних [10]. Ця регресійна залежність в діапазоні температур $T=273 \ldots 403 \mathrm{~K}$ має вигляд:

$$
D(T)=-4,12+0,025 T-2,574 \cdot 10^{-5} T
$$

де: $D(T)=D / D_{298} ; D-$ значення коефіцієнта дифрузії при температурі, відмінній від 298 K; $D_{298}$ - коефіцієнт дифузії при температурі $298 \mathrm{~K}$.

Концентращію насичення палива воднем при тиску 0,1 МПа визначимо на підставі регресійних залежностей, наведених у роботі [3]. Дані по насиченню різних палив воднем при тиску 0,1 МПа та температурі $T=298 \mathrm{~K}$ наведено у табл. 1.

Чисельне рішення рівняння (1) на прикладі дизельного палива, при середній температурі краплі палива виконувались у два етапи: на першому етапі визначався загальний характер розподілу концентрації водню в середньому перетині краплі і в шарі повітря біля краплі; на другому етапі визначалась зона зміни концентрації водню в шарі палива біля поверхні контакту фраз

На рис. 1 наведено загальний характер розподілу концентрації водню в середньому перетині краплі і в шарі повітря біля краплі.

Дані наведені на рис. 1, отримані для краплі паливо-водневої суміші з діаметром 25 мкм. Концентрації водню в повітрі визначалась в зоні 50 мкм від поверхні краплі палива. Тип палива - дизельне. Початкова температура - 323 К. Час існування краплі 3 моменту вприскування в циліндр ДВЗ до моменту займання - 0,1 с. Площі, пофарбовані синім кольором відображають характер зміни концентрації водню в повітрі, біля поверхні краплі. Площа пофрарбована червоним кольором, відображає характер зміни концентрації водню в середньому перетині краплі. Чисельне рішення рівняння (1) для зазначених умов (рис. 1 б) показуе, що за час $\tau=0,1$ с відбуваються незначні зміни концентрації водню в прикордонних шарах рідини і повітрі біля поверхні контакту фраз. На рис. 2 наведено загальний характер розподілу концентрації водню в шарі палива, біля поверхні контакту фаз. Початкові і граничні умови вирішення відповідають початковим і граничним умовам попереднього рішення диференціального рівняння (1).

Дані рис. 2 показують, що при прийнятих початкових і граничних умовах рішення рівняння (1) зона дифузії водню у краплі не перевищуе 1 мкм. Зона зміни концентрації водню у прикордонному шарі повітря біля поверхні розподілу фраз, не перевищуе $3 . . .4$ мкм.

\section{Розчинність водню в паливі}

Таблиця 1

\begin{tabular}{|l|c|c|c|c|c|c|c|}
\hline Тип палива & $\mathrm{K}$ & $\mathrm{DF}$ & $\mathrm{FO}$ & LVGO & HVGO & GDAR & ABVB \\
\hline Розчинність , $\mathbf{m}^{3} / \mathrm{M}^{3}$ & 0,363 & 0,405 & 0,309 & 0,359 & 0,198 & 0,097 & 0,099 \\
\hline
\end{tabular}

де: $K$ - керосин; DF - дизельне паливо; FO - мазут; $L V G O$ - легкий газойль; $H V G O$ - важкий газовий мазут; GDAR - атмосферний залишок GuDao; $A B V B$ - вакуумний залишок. 


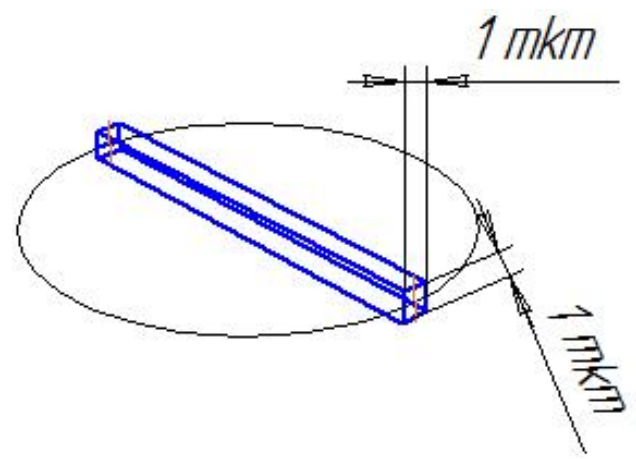

a)

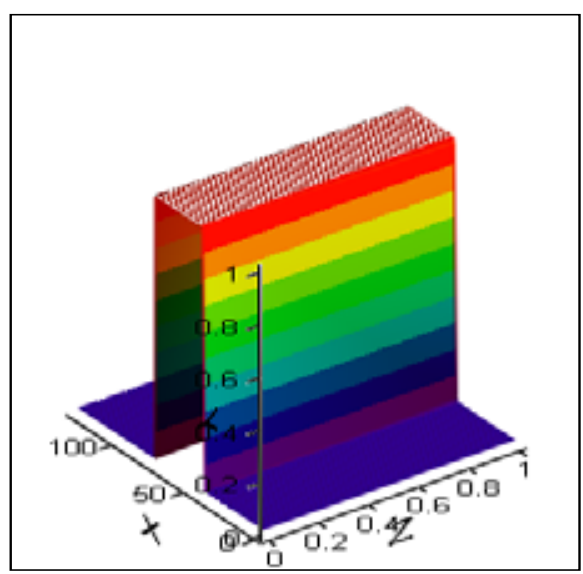

б)

Рис. 1. Середній перетин краплі з елементарним об'емом (а) та розподіл концентрації водню в краплі і навколишньому повітрі (б)

$\mathrm{X}, \mathrm{Y}, \mathrm{Z}$ - довжина, висота і ширина елементарного об’ему краплі палива

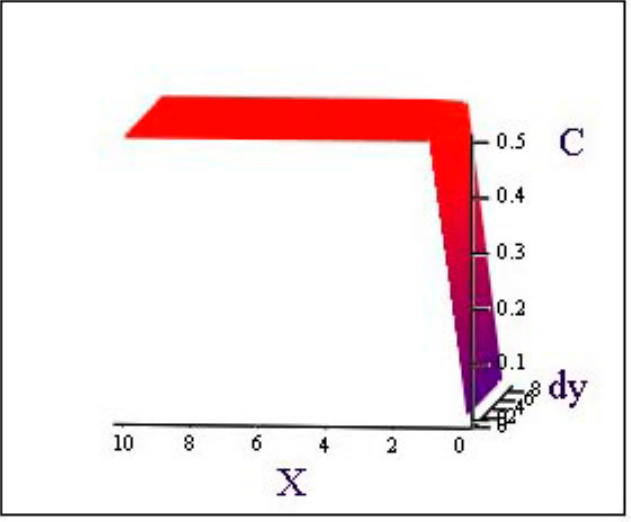

a)

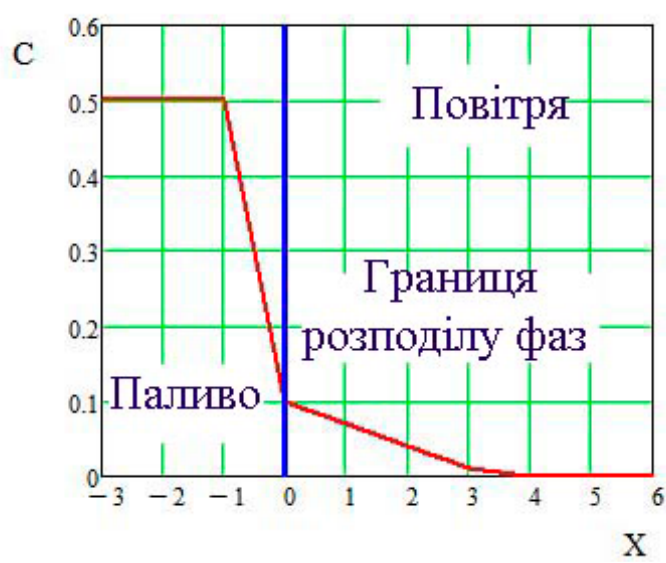

б)

Рис. 2. Розподіл концентрації водню в краплині палива біля поверхні контакту фаз ( $x$-координата по діаметру краплі, мкм; $C$-концентрація водню в краплі та у повітрі, $\mathbf{m}^{3} / \mathbf{m}^{3}$; вісь $d y$-розмір поперечного перерізу об'ему краплі палива, мкм)

Стає доцільним визначити залежність зони зміни концентрації водню біля межі фраз з боку палива в залежності від значення коефіціенту дифузії водню в паливі. Данні розрахунків показали, що для значення коедіцієнту дифрузії водню $D=1 \cdot 10^{-9} \mathrm{M}^{2} /$ с глибина слою дифузії становить $l d=0,83 \cdot 10^{-6} \mathrm{M}$, а для $D=10 \cdot 10^{-9} \mathrm{M}^{2} / \mathrm{c}-l d=1 \cdot 10^{-6} \mathrm{M}$.

Узагальнення численних рішень рівняння (1) для діапазону коефіцієнтів дифузії водню у паливі $D=1 \cdot 10^{-9} \ldots 10 \cdot 10^{-9} \mathrm{M}^{2} / \mathrm{c}$ дає наступне регресійне рівняння зміни дифузійної зони в краплі:

$l d=8,139 \cdot 10^{-7}+15,833 \cdot D+2,778 \cdot 10^{-8} \cdot D^{2}, \mathcal{M}$ (3)

У процесі десорбції водню 3 палива в прикордонному шарі повітря, що оточуе краплину палива, зростає концентрація $\mathrm{H}_{2}$, виникає необхідність оцінки концентраційного рівня водню в граничному шарі повітря, біля краплі палива, i зміни температури повітря в цьому шарі в разі самозаймання водню.

Візьмемо товщину шару дифрузії водню в краплині палива рівною 1 мкм, і товщину прикордонного шару повітря біля краплі палива 3 мкм, для початкової концентрації $\mathrm{H}_{2}$ в паливі $C t=0,4 \mathrm{M}^{3} / \mathrm{M}^{3}$ (дизельне паливо) отримаємо значення концентрації $\mathrm{H}_{2}$ в цьому шарі повітря $\mathrm{C}=5,1 \%$. Тобто в прикордонному шарі повітря у краплі паливно- водневої суміші утворюеться нижня межа концентрації, при якій виникає самозаймання $\mathrm{H}_{2}$ [12]

Оцінка зміни температури повітря в цьому прикордонному шарі при вище прийнятій початковій концентрації водню в паливі дає $\Delta T=60 \ldots 63^{\circ} \mathrm{C}$ в порівнянні $з$ температурою повітря далеко від краплі палива. Таким чином інтенсифрікуеться процес нагріву палива, що покращує процес його згоряння.

Данні розрахунків наведено на рис.3.

Для діапазону зміни концентрації водню у паливі $C t=0,1 \ldots 1,0 \mathrm{~m}^{3} / \mathrm{M}^{3}$ дані рис. 3 апроксимуються наступними регресійними залежностями

$$
\begin{aligned}
\Delta T(C t) & =1,06+155,55 \cdot C t,{ }^{\circ} \mathrm{C} \\
C g(C t) & =10 \cdot 10^{-3}+12,7 \cdot C t, \%
\end{aligned}
$$

Висновки 3 даного дослідження i перспективи. Теоретичний аналіз десорбції водню 3 насиченого ним палива показує:

- в період часу з моменту подачі гомогенної паливо-водневої суміші у циліндр ДВЗ, до моменту початку займання палива, 3 нього десорбується незначна частина водню, яким воно було попередньо насичено.

- глибина зони дифузії у краплині палива за зазначений вище час не перевішуе 1 мкм від поверхні контакту фраз; 


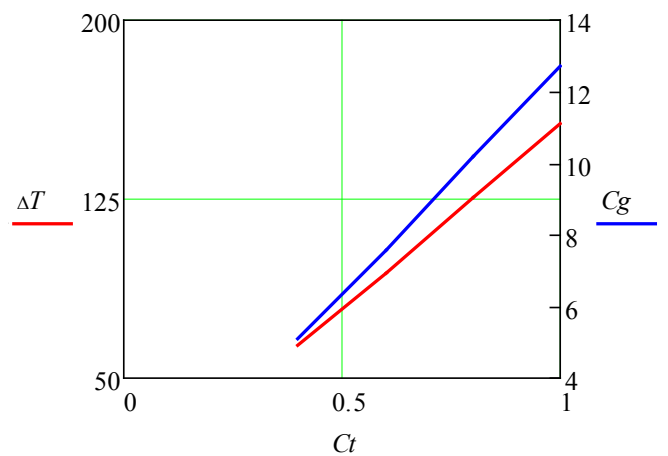

Рис. 3. Зміна температури $\Delta T$

та концентрація водню $\mathrm{Cg}$ в прикордонному шарі повітря, для краплі палива в залежності від насичення палива воднем $C t\left(\mathbf{m}^{3} / \mathbf{M}^{3}\right)$
- кількість десорбованого водню 3 краплі палива достатня для виникнення процесу самозаймання водню в прикордонному шарі повітря у поверхні контакту фраз;

- кількість десорбованого водню з краплі палива достатня для підвищення температури в прикордонному шарі повітря у поверхні контакту фраз мінімум на $60^{\circ} \mathrm{C}$.

Це дає можливість зробити висновок, що десорбція невеликої кількості водню з краплі паливо-водневої суміші дозволяе інтенсифрікувати процес горіння палива за рахунок інтенсифікації розігріву краплі при самозайманні водню у прикордонному шарі повітря. Що повинно призвести до підвищення ефективності теплової машини при використанні паливо-водневої суміші. Данні теоретичного аналізу необхідно перевірити на діючих двигунах внутрішнього згорання.

\section{Список літератури:}

1. Коробейников С.М., Соловейчик Ю.Г., Бычков А.Л. Растворение пузырьков диагностических газов в трансформаторном масле. Теплофбзика высоких телператур. 2011. Т. 49. Вып. 5. С. 771-77.

2. Лейбович Л.І., Євстигнеєв Ю.В. Використання паливо-водневих сумішей у теплових двигунах. Суднова енергетика: стан та проблеми: матеріали VIII Міжнародної наук.-техн. конфр. (Миколаїв, 8-10 листопада 2017 р.). Миколаїв : НУК ім. адмірала Макарова, 2017. С. 324-327.

3. Лейбович Л.И., Евстигнеев Ю.В. Растворимость водорода в жидких топливах при атмосферном давлении. Modernen gineering andinnovative technologies. October 2018. Issue № 5, vol. 3, pp. 46-50.

4. Лейбович Л.И., Пацурковский П.А. Окисление сероводорода во влажном воздухе. Вестник Харьковского национального автомобильно-дорожного университета. 2015. Вып. 71. С. 85-90.

5. Лобанов М.Л., Зорина М.А. Методы определения коэффициентов диффрузии : учеб. пособие. Екатеринбург, 2017. $100 \mathrm{c}$

6. Магульский Р.Ф. Дисперсность и структура дизельной сажи. Токсичность двигателей внутреннего сгорания и некоторые пути их уленьшения. Москва : ЦНИТА, 1966. С. 206-219.

7. Миклос А.Г., Чернявская Н.Г., Червяков С.П. Судовые двигатели внутреннего сгорания. Ленинград, 1986.360 с.

8. Новосёлов С.В. Использование водорода в качестве моторного топлива. Теплоэнергетика. 1996. № 2. С. $27-28$.

9. Певнев Н.Г., Пономарчук В.В. Перспективы комбинирования моторного топлива путем применения водородосодержащей добавки. Вестник СибАДИ. 2016. Вып. 2(48). С. 75-80.

10. Смыгалина А.Е. Горение смесей на основе водорода в газопоршневом двигателе. Известия акаделии наук энергетика. 2015. № 2. C 120-130.

11. Хоблер Т. Массопередача и абсорбция. Ленинград, 1964. 479 с.

12. Хомяков В.Г., Машовец В.П., Кузьмин Л.Л. Технология әлектрохимических производств. Москва, 1949.674 с.

13. Хрипач Н.А. Разработка водородной энергоустановки новой генерации. Известия МГТУ «МАМИ», № 1(13). 2012. C. 96-101.

\section{References:}

1. Korobeinykov, S.M., Soloveichyk, Yu.H., \& Buchkov, A.L. (2011). Rastvorenye puzbrkov dyahnostycheskykh hazov v transformatornom masle [Dissolution of bubbles of diagnostic gases in transformer oil]. Teplofyzyka vusokykh temperatur. T. 49, vol. 5, pp. 771-77.

2. Leibovych, L.I., \& Yevstyhnieiev, Yu.V. (2017). Vykorystannia palyvo-vodnevykh sumishei u teplovykh dvyhunakh [The use of fuel-hydrogen mixtures in heat engines]. Proceedings of the Sudnova enerhetyka: stan ta problemy (Ukrainian, Mykolayiv, 8-10 lystopada 2017 r.). Mykolayiv: NUK im. admirala Makarova, pp. 324-327.

3. Leibovych, L.I., \& Yevstyhnieiev, Yu.V. (2018). Rastvorymost vodoroda v zhydkykh toplyvakh pry atmosfernom davlenyy [Hydrogen solubility in liquid fuels at atmospheric pressure]. Modernen gineering andinnovative technologies. Vol. 3, pp. 46-50.

4. Leibovych, L.Y., \& Patsurkovskyi, P.A. (2015). Okyslenye serovodoroda vo vlazhnom vozdukhe [Oxidation of hydrogen sulfide in moist air]. Vestnyk Kharkovskoho natsyonalnoho avtomobylno-dorozhnoho unyversyteta, vol. 71, pp. 85-90.

5. Lobanov, M.L., \& Zoryna, M.A. (2017). Metody opredelenyya koéffytsyentov dyffuzyy [Methods for determining diffusion coefficients]. Ekaterynburh. (in Russian)

6. Mahulskyi, R.F. (1966). Dyspersnost y struktura dyzelnoi sazhy [Dispersion and structure of diesel soot]. Toksychnost dvyhatelei vnutrenneho shoranyia y nekotorue puty ykh umenshenyia. Moskva: TsNYTA, pp. $206-219$.

7. Myklos, A.H., Cherniavskaia, N.H., \& Cherviakov, S.P. (1986). Sudovue dvyhately vnutrenneho shoranyia [Marine internal combustion engines]. Lenynhrad. (in Russian)

8. Novoselov, S.V. (1996). Yspolzovanye vodoroda v kachestve motornoho toplyva [Use of hydrogen as a motor fuel]. Teploenerhetyka, no. 2, pp. 27-28.

9. Pevnev, N.H., \& Ponomarchuk, V.V. (2016). Perspektyvy kombynyrovanyia motornoho toplyva putem prymenenyia vodorodosoderzhashchei dobavky [Prospects for combining motor fuel through the use of hydrogen-containing additives]. Vestnyk SybADY, vol. 2(48), pp. 75-80.

10. Smuhalyna, A.E. (2015). Horenye smesei na osnove vodoroda $\mathrm{v}$ hazoporshnevom dvyhatele [Combustion of hydrogen-based mixtures in a gas engine]. Yzvestyia akademyy nauk enerhetyka, no. 2, pp. 120-130.

11. Khobler, T. (1964). Massoperedacha y absorbtsyia [Mass transfer and absorption]. Lenynhrad. (in Russian)

12. Khomiakov, V.H., Mashovets, V.P., \& Kuzmyn, L.L. (1949). Tekhnolohyia elektrokhymycheskykh proyzvodstv [Technology of electrochemical production]. Moskva. (in Russian)

13. Khrypach, N.A. (2012). Razrabotka vodorodnoi enerhoustanovky novoi heneratsyy [Development of a new generation hydrogen power plant]. Yzvestyia MHTU "MAMY", vol. 1(13), pp. 96-101. 